\title{
Analysis of different molecular methods for typing methicillin-resistant Staphylococcus aureus isolates belonging to the Brazilian epidemic clone
}

\author{
MARIA J. DOS SANTOS SOARES*†, LENISE A. TEIXEIRAł, MARIA DO ROSÁRIO NUNES†, \\ MARIA C. DA SILVA CARVALHO*, BERNADETE T. FERREIRA-CARVALHO* and \\ AGNES M. S. FIGUEIREDO*
}

* Universidade Federal do Rio de Janeiro, Instituto de Microbiologia Prof. Paulo de Góes, Laboratório de Biologia Molecular de Bactérias, CCS, Bloco I, Cidade Universitária, Rio de Janeiro, RJ 21941-590, †Universidade Federal do Piauí, CCS, Departamento de Parasitologia e Microbiologia, SG16, Teresina, PI 64049-550 and +Universidade Federal Fluminense, Departamento de Tecnologia Farmacêutica, Faculdade de Farmácia, Niterói, Rio de Janeiro, RJ 24241-002, Brazil

\begin{abstract}
The extensive geographic spread of MRSA isolates belonging to the Brazilian epidemic clone (BEC) limited the value of pulsed-field gel electrophoresis (PFGE) in epidemiological studies of outbreaks caused by these strains. Thus, the discriminatory power of eight different molecular methods was evaluated in an attempt to establish a methodology for genotyping BEC isolates involved in intra-hospital outbreaks. BEC isolates from five hospitals in Teresina City, Piauí State were genotyped by conventional electrophoresis or PFGE of ClaI- or SmaI-digested genomic DNA hybridised with specific labelled mec $A$, Tn554, IS257 and IS256 probes. The combination of PFGE with ClaI/mecA, ClaI/Tn554, ClaI/IS257, SmaI/mecA and SmaI/IS257 probe-fingerprinting techniques provided a very poor discriminatory power for BEC strains. Although Cla I/ IS256 fingerprinting discriminated 17 different polymorphisms among the isolates displaying PFGE $A_{1}$ pattern, this strategy was not reproducible. In contrast, the combination of PFGE and Sma I/IS256 polymorphisms differentiated BEC isolates into nine stable polymorphisms. Thus combination of PFGE and hybridisation with IS256 probe may be recommended as a useful means of typing BEC strains involved in intrahospital infections.
\end{abstract}

\section{Introduction}

Methicillin-resistant Staphylococcus aureus (MRSA) is a common hospital pathogen world-wide and may be a cause of severe infections in which its multiple antibiotic resistance is a serious complication [1-3].

MRSA strains were first reported in the UK in 1961, soon after the introduction of $\beta$-lactamase-resistant penicillin in clinical therapy [4]. Epidemics caused by MRSA were described in Australian hospitals in the early 1980s by Pavillard and co-workers [5]. Later, it

Received 24 July 2000; revised version accepted 24 Jan. 2001.

Corresponding author: Dr A.M.S. Figueiredo (e-mail address: immmasf@microbio.ufrj.br). was demonstrated that the Australian clone had also appeared in different regions of the UK $[6,7]$. Because of their ability to spread quickly, these MRSA isolates were called epidemic methicillin-resistant Staphylococcus aureus-1 (EMRSA-1) [8].

The extensive geographic spread of specific clones of MRSA has also been reported by others [9-21]. The Iberian clone, a well-characterised epidemic MRSA, was initially detected in an outbreak in the Bellvitge Hospital in Barcelona, Spain, in 1989 [9]. Later, this MRSA clone was detected in at least eight Portuguese hospitals, as well as in Scotland, Italy, Belgium, Germany and New York $[11-13,16,17]$. In 1999, SáLeão and co-workers described the intercontinental spread of another unique clone defined and seen as characteristic of infections in paediatric patients in Portugal, Poland, Argentina, Colombia and New York [18]. The predominance of specific MRSA clones was also observed in Turkey, Spain, France, Germany, 
Belgium and Japan [22-24]. Recently, Da Silva Coimbra et al. described the spread and predominance of two unique MRSA clones in hospitals located in different cities on the coast of the USA [21].

In Brazil, a unique multiresistant $S$. aureus clone (Brazilian epidemic clone, BEC) is disseminated in different hospitals from the north to the south of the country [10, 25-27]. BEC has also been detected as the cause of invasive infections in other South American countries (Argentina and Uruguay) and in Europe (Portugal and the Czech Republic) [14, 15, 19, 20]. More recently, the analysis of a small collection of MRSA, obtained from a Canadian hospital in the early 1990s, provided evidence that a cluster of strains all resembling $\mathrm{BEC}$ isolates or related genotype was spread in that hospital [28].

Besides the social and economic problems caused by the epidemic spread of specific clones of MRSA in hospitals, the extensive dissemination of a unique clone type limits the analysis of outbreaks, as all isolates involved have the same or very similar pulsed-field gel electrophoresis (PFGE) patterns. Thus, the discriminatory power of PFGE for genotyping MRSA strains displaying the same or very similar profiles became reduced [29].

Kreiswirth et al., in 1993, studied the clonal origin of the mecA gene by analysis of a collection of MRSA isolates from different time periods and geographic locations. By digesting the DNA of these strains with the endonuclease $\mathrm{Cla}$ I and hybridising the fragments obtained with mecA or Tn554 DNA probes, they distinguished six $C l a \mathrm{I} / m e c A$ polymorphisms (I-VI) and $29 \mathrm{Cla} / \mathrm{Tn} 554$ patterns based on the location of the mecA gene and the Tn554 transposon insertions in the bacterial genome, respectively [30]. Since the publication of these studies, other workers have used Cla $\mathrm{I} / m e c A, C l a \mathrm{I} / \mathrm{Tn} 554$ and SmaI/mecA polymorphisms to characterise the genomic diversity of MRSA hospital isolates $[10,12,17,19]$.

The use of insertion sequence (IS)-based probes is becoming an increasingly important tool in genetic discrimination of bacterial strains [23, 31-37]. Insertion sequences are small mobile elements (c. 0.7$1.5 \mathrm{~kb}$ ), usually composed of a single gene encoding a transposase, flanked by short inverted repeated sequences [38]. Two IS sequences (IS257 and IS256) are well characterised IS elements in $S$. aureus $[39,40]$. More recently, the combination of IS257 or IS256 probe-fingerprinting with PFGE has been used to further discriminate $S$. aureus isolates [23, 34].

This study evaluated the discriminatory power of eight different DNA methods, commonly used for MRSA genotyping, in an attempt to establish a methodology that would help in studies of molecular epidemiology of outbreaks involving BEC isolates.

\section{Materials and methods}

\section{Bacterial isolates}

A total of 84 MRSA clinical isolates was obtained during 1996-1998, from five hospitals located in Teresina City, Pi. The isolates were collected from different infection sites of patients hospitalised in several wards. Only one isolate was obtained from each patient presenting with hospital infection, except for seven patients, from whom two or three isolates were collected. Three further BEC isolates obtained from our laboratory collection were used to evaluate the reproducibility of the methods.

\section{PFGE and conventional electrophoresis (CE)}

Agarose inserted genomic DNA was prepared as described previously [41]. PFGE of Sma I-digested DNA was also performed as described previously [41]. In another approach, the agarose inserted DNA was digested with Cla I (Amersham Pharmacia, Piscataway, NJ, USA) and CE was run at $38 \mathrm{~V}$ for $14 \mathrm{~h}$ in $1 \times$ TAE buffer.

\section{Probe preparation}

The Escherichia coli plasmids, which contain the DNA fragments used as probes, were prepared with a FlexPrep Kit (Amersham Pharmacia) as recommended by the manufacturer. The DNA fragments of E. coli plasmids were purified electrophoretically from an agarose $0.8 \%$ gel with a Sephaglas Band-Prep kit (Amersham Pharmacia) according to the manufacturer's recommendations. The procedures to obtain non-radioactive labelled probes by the ECL direct nucleic acid labelling and detection system (RPN3000; Amersham Pharmacia) were also performed according to the manufacturer's instructions. The mecA DNA probe used was a 1196-bp Pst I-XbaI fragment of the mecA gene cloned into pTZ19 [42]. A 5.5-kb EcoRV transposon-specific fragment was used to detect the Tn554 [30]. The IS257 probe was a 630-bp HindIII fragment cloned in pIB1644 and the IS256 DNA probe was the 468-bp fragment obtained by PCR, as described above [43].

Primers 1 (5'- CAGAACAGCTGGATCCTATGG-3') and 2 (5'- GTCGACTTTTAGCCTCACGCG-3') were purchased from Gibco/BRL (Life Technologies, Rockville, USA). These primers correspond to bp 523-543 and 990-970 of the IS256 sequence and lead to the amplification of a 468-bp fragment from within ORF390 of the IS256 [31,44]. DNA amplification was performed in $50 \mu \mathrm{l}$ of reaction mixture which contained $200 \mathrm{ng}$ of the template DNA; $400 \mu \mathrm{M}$ each of dATP, dCTP, dGTP and dTTP; $0.4 \mu \mathrm{M}$ of each primer and $1 \times$ PCR buffer (Amersham Pharmacia). A volume corresponding to $2.5 \mathrm{U}$ of Taq DNA polymerase (Amersham Pharmacia) was added only after the pre-denaturation step. Cycling was performed in a GeneAmp PCR System 9700 (Perkin-Elmer Applied 
Biosystems, Foster City, CA, USA) with the following programme: pre-denaturation at $94^{\circ} \mathrm{C}$ for $5 \mathrm{~min}$ and 25 cycles of $30 \mathrm{~s}$ at $94^{\circ} \mathrm{C}, 30 \mathrm{~s}$ at $60^{\circ} \mathrm{C}$ and $1 \mathrm{~min}$ at $72^{\circ} \mathrm{C}$, and with a final $5 \mathrm{~min}$ extension step at $72^{\circ} \mathrm{C}$. A $5-\mu \mathrm{l}$ sample of the PCR product was run in an agarose $1.5 \%$ gel electrophoresis in $1 \times$ TAE buffer. The 468-bp PCR product was purified with the Sephaglas BandPrep Kit, as recommended by the manufacturer.

\section{Blotting and hybridisation experiments}

DNA fragments from PFGE and CE were transferred to Hybond $\mathrm{N}+$ nylon membrane (Amersham Pharmacia) by vacuum transfer of DNA (VacuGene XL; Amersham-Pharmacia) in an alkaline solution $(0.5 \mathrm{M} \mathrm{NaOH}$, $1.5 \mathrm{M} \mathrm{NaCl}$, final concentrations), according to the manufacturer's instructions. The DNA was fixed by baking at $80^{\circ} \mathrm{C}$ for $2 \mathrm{~h}$. After hybridisation with the mecA probe, the DNA was re-probed (after being stripped by boiling) with Tn554, IS256 and IS257 probes. The hybridisation procedures were performed following the methodology described in the ECL protocol.

\section{Criteria for interpreting PFGE and probe- fingerprinting techniques}

Strains showing the same PFGE pattern or differing by one-to-three bands were grouped in a type (clone) and assigned the same capital letter. Numeric subcodes were used to represent differences (subtypes or subclones). The prevalent isolate of a type was assigned the capital letter and subcode 1 and used as the standard strain for analysing band differences. Isolates that differed by four-to-six PFGE fragments were grouped in a different but closely related type that was assigned to a different capital letter. Finally, MRSA isolates that differed by seven or more PFGE fragments were considered to be a different and unrelated type and were also assigned a different capital letter [10].

Isolates displaying the same Cla I/IS256 polymorphisms were assigned the same capital letter and numerical index. Strains differing by only one-to-three bands from the dominant type $\left(\mathrm{A}^{1}\right)$ were assigned a different numerical index, to facilitate the analysis and presentation of the data. Thus, MRSA isolates with patterns that differed in up to three bands were classified in subtypes. Finally, isolates differing by four or more bands were assigned a different capital letter.

The SmaI/IS256 polymorphisms of isolates that displayed the same hybridisation pattern were grouped in the same genotype and identified by the same Roman numeral. The patterns that displayed one or more different bands were grouped in a different genotype using different numerals. The SmaI endonuclease enzyme has a relatively small number of restriction sites in the $S$. aureus genome. Because it would be very rare to detect a genetic event involving these sites during the course of a hospital outbreak, the criterion of one band difference was chosen to define the SmaI/IS256 genotype. To facilitate the visual analysis of the patterns only hybridised fragments $\geqslant 48.5 \mathrm{~kb}$ were considered.

\section{Reproducibility assay}

To investigate the frequency of genetic changes in the $S$. aureus DNA, three MRSA isolates displaying different but similar PFGE patterns were submitted to 30 serial passages on Tryptic Soya Agar. Another three pairs of MRSA isolates obtained from three different patients, during a period of about 1 week, 1 month or 2 months, respectively, were also analysed. These pairs formed by the strains 109 and 117; 86 and 107; and 11 and 56 were chosen because each strain of a pair displayed the same PFGE pattern and $S m a \mathrm{I} / m e c A$, SmaI/IS257, ClaI/mecA,ClaI/IS257 and ClaI/Tn554 polymorphisms, as well.

\section{Results}

$P F G E$

A total of 78 MRSA resembling BEC strains was obtained from the collection of 84 MRSA isolates associated with hospital infections, in patients from five hospitals located in Teresina City, Pi (Table 1). The isolates were collected from March 1996 to July 1998. All these 78 MRSA isolates had very similar PFGE patterns, referred to here as pattern A (Fig. 1). Fiftyseven (c. 70\%) of the MRSA strains shared the same predominant PFGE pattern $\mathrm{A}_{1}$ (Table 1), previously described among the BEC isolates from Brazil [10]. Twenty-one MRSA strains differed from the BEC $\mathrm{A}_{1}$ pattern by only one, two or three PFGE bands. Thus, besides pattern $A_{1}$, six other subtypes $\left(A_{2}-A_{7}\right.$, Fig. 1) were detected. Among these variants, subtype $\mathrm{A}_{2}$ was the most frequent (13 strains), followed by $\mathrm{A}_{4}$ (four strains). The absolute predominance of BEC strains in Brazil and the wide spread of this clone type to other countries limited the discriminatory power of PFGE for genotyping these MRSA isolates $[10,14,15,19,20$, 25-27].

\section{Characterisation of the MRSA isolates by traditional DNA fingerprinting methods (ClaI/ mecA, ClaI/Tn554 and SmaI/mecA polymorphisms) for typing of MRSA isolates}

This study tested the 78 BEC isolates by the methodologies described by Kreiswirth et al. [30]. The different patterns obtained are listed in Table 1.

The great majority of the BEC isolates studied (71 of 78) had the same $C l a \mathrm{I} / m e c A$ polymorphism (here called pattern $\mathrm{III}_{1}$ ), except seven that gave pattern III. 
Table 1. Genotypic characterisation of $78 \mathrm{MRSA}$ isolates from five hospitals in Teresina City, Pi

\begin{tabular}{|c|c|c|c|c|c|c|c|c|}
\hline \multirow[b]{2}{*}{ Strain no. } & \multicolumn{8}{|c|}{ Genomic patterns* } \\
\hline & PFGE & $\begin{array}{l}\text { SmaI } \\
\text { mecA }\end{array}$ & $\begin{array}{l}\text { SmaI } \\
\text { IS257 }\end{array}$ & $\begin{array}{l}\text { Cla I } \\
\text { mecA }\end{array}$ & $\begin{array}{l}\text { Cla I } \\
\text { IS } 257\end{array}$ & $\begin{array}{l}\text { Cla I } \\
\text { Tn554 }\end{array}$ & $\begin{array}{l}\text { SmaI } \\
\text { IS256 }\end{array}$ & $\begin{array}{l}\text { Cla I } \\
\text { IS256 }\end{array}$ \\
\hline 01,14 & $\mathrm{~A}_{1}$ & $\mathrm{G}$ & $a_{1}$ & III & $\alpha$ & $\mathrm{B}_{1}$ & I & $\mathrm{A}^{14}$ \\
\hline 02 & $A_{1}$ & G & $a_{1}$ & $\mathrm{III}_{1}$ & $\alpha$ & $\mathrm{B}$ & IV & $\mathrm{A}^{16}$ \\
\hline 03 & $\mathrm{~A}_{4}$ & G & $a_{1}$ & $\mathrm{III}_{1}$ & $\alpha$ & $\mathrm{B}_{1}$ & $\mathbf{X I}$ & $\mathrm{A}^{2}$ \\
\hline $04,06,10,11,24,51,56,74,84,87,93,98$ & $\mathrm{~A}_{1}$ & G & $a_{1}$ & $\mathrm{III}_{1}$ & $\alpha$ & $\mathrm{B}_{1}$ & $\mathbf{I}$ & $\mathrm{A}^{1}$ \\
\hline 08 & $\mathrm{~A}_{4}$ & G & $a_{1}$ & III & $\alpha$ & $\mathrm{B}_{1}$ & XIV & ND \\
\hline $09,13,49,53,54$ & $A_{1}$ & G & $a_{1}$ & $\mathrm{III}_{1}$ & $\alpha$ & $\mathrm{B}_{1}$ & $\mathbf{V}$ & $\mathrm{A}^{10}$ \\
\hline 12 & $\mathrm{~A}_{1}$ & G & $a_{1}$ & $\mathrm{III}_{1}$ & $\alpha$ & $\mathrm{B}$ & IV & $\mathrm{E}$ \\
\hline 16 & $\mathrm{~A}_{1}$ & G & $a_{1}$ & $\mathrm{III}_{1}$ & $\alpha$ & $\mathrm{B}_{1}$ & Viii & $\mathrm{A}^{10}$ \\
\hline $17,39,88$ & $\mathrm{~A}_{1}$ & G & $a_{1}$ & $\mathrm{III}_{1}$ & $\alpha$ & $\mathrm{B}_{1}$ & III & $\mathrm{A}^{1}$ \\
\hline 20 & $\mathrm{~A}_{1}$ & G & $a_{1}$ & $\mathrm{III}_{1}$ & $\alpha$ & $\mathrm{B}$ & III & $\mathrm{G}$ \\
\hline $21,64,66,72,73,109,117$ & $\mathrm{~A}_{1}$ & G & $a_{1}$ & $\mathrm{III}_{1}$ & $\alpha$ & $\mathrm{B}_{1}$ & VIII & $\mathrm{A}^{2}$ \\
\hline 48 & $\mathrm{~A}_{1}$ & G & $a_{1}$ & III & $\alpha$ & $\mathrm{B}_{1}$ & III & $\mathrm{A}^{14}$ \\
\hline 50 & $\mathrm{~A}_{1}$ & G & $a_{1}$ & III & $\alpha$ & $\mathrm{B}_{1}$ & I & $\mathrm{A}^{1}$ \\
\hline 57,113 & $\mathrm{~A}_{1}$ & G & $a_{1}$ & $\mathrm{III}_{1}$ & $\alpha$ & $\mathrm{B}_{1}$ & $\mathbf{V}$ & $\mathrm{A}^{1}$ \\
\hline 61 & $\mathrm{~A}_{1}$ & G & $a_{1}$ & $\mathrm{III}_{1}$ & $\alpha$ & $\mathrm{B}_{1}$ & $\mathbf{I}$ & $\mathrm{A}^{15}$ \\
\hline 62 & $\mathrm{~A}_{4}$ & G & $a_{1}$ & III & $\alpha$ & $\mathrm{B}_{1}$ & XI & $\mathrm{A}^{2}$ \\
\hline 65 & $\mathrm{~A}_{1}$ & G & $a_{1}$ & $\mathrm{III}_{1}$ & $\alpha$ & $\mathrm{B}_{1}$ & VIII & $\mathrm{A}^{13}$ \\
\hline 69,94 & $\mathrm{~A}_{1}$ & G & $a_{1}$ & $\mathrm{III}_{1}$ & $\alpha$ & $\mathrm{B}_{1}$ & I & $\mathrm{A}_{12}$ \\
\hline 78 & $\mathrm{~A}_{3}$ & G & $a_{1}$ & $\mathrm{III}_{1}$ & $\alpha$ & $\mathrm{B}_{1}$ & III & $\mathrm{A}^{18}$ \\
\hline 83 & $\mathrm{~A}_{1}$ & G & $a_{1}$ & $\mathrm{III}_{1}$ & $\alpha$ & $\mathrm{B}_{1}$ & III & $\mathrm{A}^{12}$ \\
\hline $85,89,102,105$ & $\mathrm{~A}_{2}$ & G & $a_{2}$ & $\mathrm{III}_{1}$ & $\alpha$ & $\mathrm{B}_{1}$ & I & $\mathrm{A}^{10}$ \\
\hline 86 & $\mathrm{~A}_{2}$ & G & $a_{2}$ & $\mathrm{III}_{1}$ & $\alpha$ & $\mathrm{B}_{1}$ & I & $\mathrm{A}^{3}$ \\
\hline 90 & $\mathrm{~A}_{5}$ & G & $a_{1}$ & $\mathrm{III}_{1}$ & $\alpha$ & $\mathrm{B}_{1}$ & XII & $\mathrm{B}$ \\
\hline 91,92 & $A_{1}$ & G & $a_{1}$ & $\mathrm{III}_{1}$ & $\alpha$ & $\mathrm{B}_{1}$ & II & $\mathrm{A}^{17}$ \\
\hline 100 & $\mathrm{~A}_{1}$ & $\mathrm{H}$ & $a_{2}$ & $\mathrm{III}_{1}$ & $\alpha$ & $\mathrm{B}_{2}$ & I & $\mathrm{C}$ \\
\hline 107 & $\mathrm{~A}_{2}$ & G & $a_{2}$ & $\mathrm{III}_{1}$ & $\alpha$ & $\mathrm{B}_{1}$ & I & $\mathrm{A}^{1}$ \\
\hline 111 & $\mathrm{~A}_{1}$ & G & $a_{1}$ & $\mathrm{III}_{1}$ & $\alpha$ & $\mathrm{B}_{1}$ & $\mathbf{V}$ & $\mathrm{A}^{7}$ \\
\hline 112 & $\mathrm{~A}_{1}$ & GJ & $a_{1}$ & $\mathrm{III}_{1}$ & $\alpha$ & $\mathrm{B}_{1}$ & VI & $\mathrm{A}^{1}$ \\
\hline 121 & $\mathrm{~A}_{1}$ & $\mathrm{G}$ & $a_{1}$ & $\mathrm{III}_{1}$ & $\alpha$ & $\mathrm{B}_{1}$ & VI & $\mathrm{A}^{2}$ \\
\hline 122 & $\mathrm{~A}_{1}$ & G & $a_{1}$ & $\mathrm{III}_{1}$ & $\alpha$ & B & I & $\mathrm{F}$ \\
\hline 128 & $\mathrm{~A}_{1}$ & G & $a_{1}$ & $\mathrm{III}_{1}$ & $\alpha$ & B & VII & $\mathrm{F}$ \\
\hline 130 & $\mathrm{~A}_{1}$ & G & $a_{1}$ & $\mathrm{III}_{1}$ & $\alpha$ & $\mathrm{B}_{1}$ & $\mathbf{V}$ & $\mathrm{A}^{2}$ \\
\hline 131 & $\mathrm{~A}_{1}$ & G & $a_{1}$ & $\mathrm{III}_{1}$ & $\alpha$ & $\mathrm{B}_{1}$ & VII & $\mathrm{A}^{11}$ \\
\hline 135 & $\mathrm{~A}_{2}$ & G & $a_{2}$ & $\mathrm{III}_{1}$ & $\alpha$ & $\mathrm{B}$ & I & $A^{5}$ \\
\hline 136 & $\mathrm{~A}_{6}$ & $\mathrm{CG}$ & $a_{3}$ & $\mathrm{III}_{1}$ & $\alpha$ & $\mathrm{B}_{2}$ & XIII & $\mathrm{A}^{5}$ \\
\hline 140 & $\mathrm{~A}_{2}$ & $\mathrm{G}$ & $a_{2}$ & $\mathrm{III}_{1}$ & $\alpha$ & $\mathrm{B}_{1}$ & I & $A^{6}$ \\
\hline 143,149 & $\mathrm{~A}_{2}$ & G & $a_{2}$ & $\mathrm{III}_{1}$ & $\alpha$ & $\mathrm{B}_{1}$ & I & $\mathrm{A}^{2}$ \\
\hline 144,148 & $\mathrm{~A}_{2}$ & $\mathrm{H}$ & $a_{2}$ & $\mathrm{III}_{1}$ & $\alpha$ & $\mathrm{B}_{3}$ & I & $\mathrm{A}^{2}$ \\
\hline 150,152 & $\mathrm{~A}_{1}$ & G & $a_{1}$ & $\mathrm{III}_{1}$ & $\alpha$ & $\mathrm{B}_{1}$ & I & $\mathrm{A}^{4}$ \\
\hline 151 & $\mathrm{~A}_{4}$ & G & $a_{1}$ & $\mathrm{III}_{1}$ & $\alpha$ & $\mathrm{B}_{1}$ & $\mathbf{X}$ & $\mathrm{A}^{4}$ \\
\hline 153 & $\mathrm{~A}_{1}$ & G & $a_{1}$ & $\mathrm{III}_{1}$ & $\alpha$ & $\mathrm{B}_{1}$ & VII & $\mathrm{A}^{1}$ \\
\hline 154,155 & $A_{1}$ & G & $a_{1}$ & $\mathrm{III}_{1}$ & $\alpha$ & $\mathrm{B}_{1}$ & I & $\mathrm{A}^{9}$ \\
\hline 170 & $\mathrm{~A}_{7}$ & G & $a_{1}$ & III & $\alpha$ & B & $\mathbf{X V}$ & $A^{8}$ \\
\hline 184 & $\mathrm{~A}_{1}$ & G & $a_{1}$ & $\mathrm{III}_{1}$ & $\alpha$ & B & IX & $\mathrm{D}$ \\
\hline
\end{tabular}

ND, not done.

* Chromosomal DNA was digested with SmaI or ClaI endonucleases and the fragments were separated by PFGE or conventional electrophoresis, respectively. After blotting and fixing on to nylon membranes, the digested genomic DNA was hybridised with mecA, IS257, Tn554 and IS256 specific probes (see Materials and methods).

Pattern III $_{1}$ is very similar to the pattern displayed by the standard type III, strain RN7164, a Canadian isolate recently identified as belonging to BEC clone type [28]. Also, all BEC isolates from Teresina had an identical or very similar Cla I/Tn554 pattern B to that observed for the standard type strain RN7164 [30]. The types $\mathrm{B}_{1}, \mathrm{~B}_{2}$ and $\mathrm{B}_{3}$ displayed by $\mathrm{BEC}$ isolates probably differed from the standard type $\mathrm{B}$ by only one genetic event (data not shown). Pattern $\mathrm{B}_{1}$ was the most frequent among these BEC isolates (66 strains). Another eight isolates had pattern $\mathrm{B}$. The other strains were distributed among patterns $B_{2}$ and $B_{3}$.

The great majority of BEC isolates ( 73 strains) had the $m e c A$ gene located in the same Sma I PFGE fragment (band $\mathrm{G}$ of $115 \mathrm{~kb}$ ).
The combination of PFGE pattern with the probefingerprinting techniques, described by Kreiswirth et al. [30], provided a total of 12 genotypes. However, 47 of 57 PFGE $\mathrm{A}_{1}$ isolates had the same genotype, displaying PFGE pattern $\mathrm{A}_{1}, \mathrm{Cla} \mathrm{I} / m e c A$ polymorphism $\mathrm{III}_{1}$ and Tn554 insertion pattern $\mathrm{B}_{1}\left(\mathrm{III}_{1}:: \mathrm{B}_{1}\right)$. The other $10 \mathrm{~A}_{1}$ isolates were distributed in two other patterns (Table 2).

Analysis of the discriminatory power of IS257 for differentiating MRSA isolates belonging to a unique clone type

All 78 BEC strains were grouped in a very similar SmaI/IS257 genotype. Sixty-four isolates gave the same SmaI/IS257 pattern $\mathrm{a}_{1}, 13$ displayed pattern $\mathrm{a}_{2}$ 


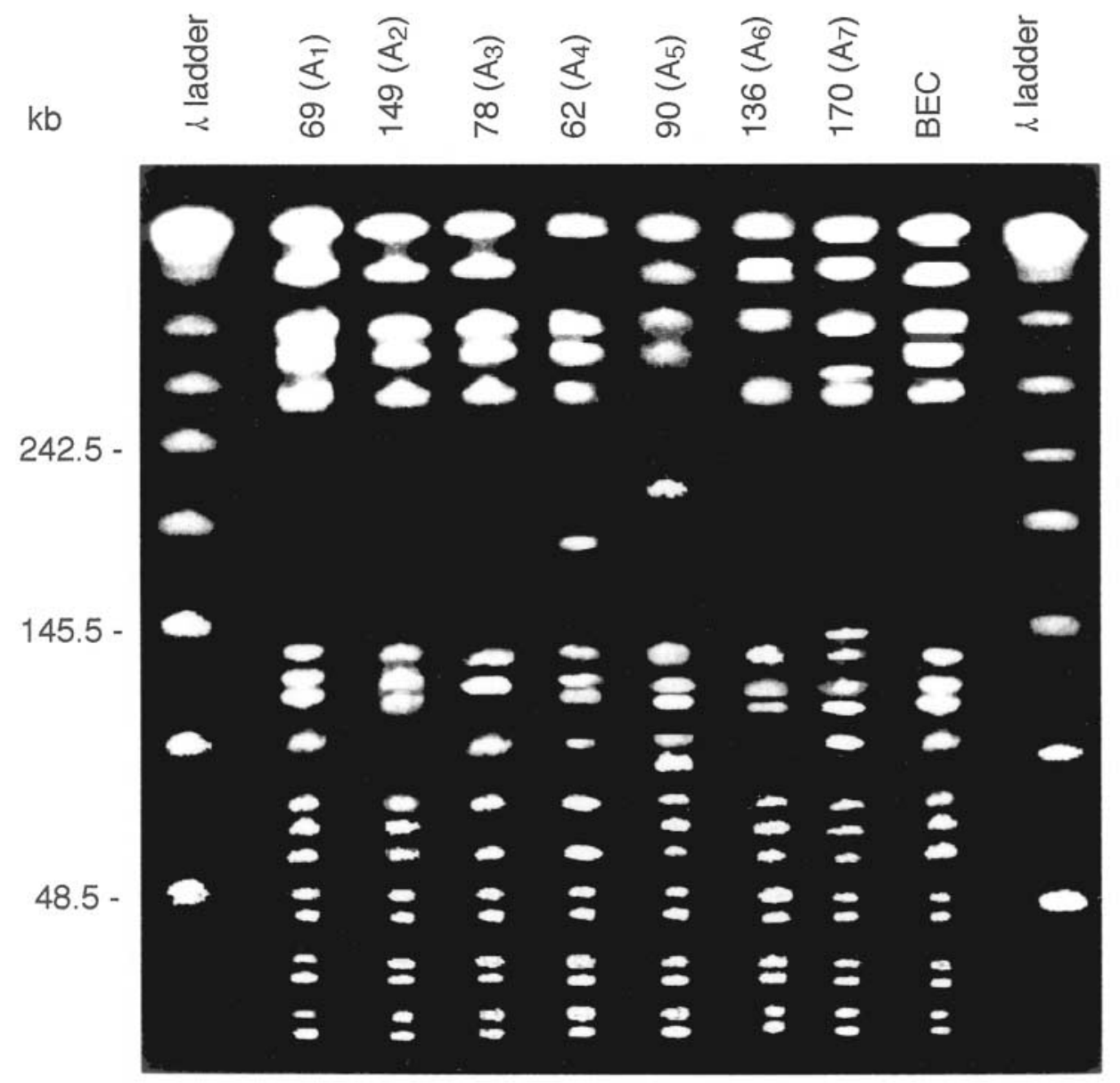

Fig. 1. Sma I PFGE patterns of MRSA isolates belonging to the BEC obtained from different hospitals in Teresina City, Pi. Lanes 1 and 10, $\lambda$ ladder; 2-8, PFGE patterns predominant in this study (patterns $A_{1}-A_{7}$, respectively); 9, pattern displayed by the strain BMB9393, a representative BEC isolate.

Table 2. Distribution of the molecular types displayed by the 57 MRSA isolates belonging to PFGE pattern $\mathrm{A}_{1}$

\begin{tabular}{|c|c|c|c|}
\hline \multicolumn{2}{|c|}{ Cla I/mecA::Cla I/Tn554* } & \multicolumn{2}{|c|}{ SmaI/IS256* } \\
\hline Pattern & $\begin{array}{c}\text { Number of } A_{1} \\
\text { isolates }\end{array}$ & Pattern & $\begin{array}{c}\text { Number of } A_{1} \\
\text { isolates }\end{array}$ \\
\hline $\mathrm{III}_{1}:: \mathrm{B}$ & 6 & I & 23 \\
\hline $\mathrm{III}_{1}:: \mathrm{B}_{1}$ & 47 & II & 2 \\
\hline III:: $\mathrm{B}_{1}$ & 4 & III & 6 \\
\hline$\ldots$ & $\ldots$ & IV & 2 \\
\hline$\ldots$ & $\ldots$ & V & 9 \\
\hline$\ldots$ & $\ldots$ & VI & 2 \\
\hline$\ldots$ & $\ldots$ & VII & 3 \\
\hline$\ldots$ & $\ldots$ & VIII & 9 \\
\hline$\ldots$ & $\ldots$ & IX & 1 \\
\hline
\end{tabular}

*Chromosomal DNA was digested with SmaI or Cla I endonucleases. The fragments were separated by PFGE or conventional electrophoresis, respectively. After blotting and fixing on nylon membranes the digested genomic DNA was hybridised with mecA, Tn554 and IS256 specific probes (see Materials and methods).

and one pattern $a_{3}$. Patterns $a_{2}$ and $a_{3}$ were verified among the isolates that had, respectively, PFGE patterns $\mathrm{A}_{2}$ and $\mathrm{A}_{6}$ (Table 1). Neither of these had PFGE band I (90 kb), displayed by BEC $A_{1}$ isolates (Fig. 1), where one insertion of the IS257 is commonly located in the BEC genome (data not shown). Thus, the changes observed in the SmaI/IS257 polymorphism were probably due to one genetic event involving the SmaI restriction site. Moreover, all the 78 isolates studied had exactly the same ClaI/IS257 polymorphism (pattern $\alpha$, Table 1). Thus, the use of either SmaI/ IS257 or ClaI/IS257 genotyping, with very rare exceptions, did not discriminate BEC isolates.

\section{Genotyping of BEC isolates with IS256 probe}

The number of bands $(9-15)$ obtained for BEC isolates with the IS256 probe indicated that the IS256 was present in numerous copies. Although the nucleotide sequence of IS256 has one Cla I restriction site located at nt 1005-1010, the probe used in the present study (nt 523-990) does not include this site [44]. Furthermore, Sma I sites are not present in the IS256 sequence. Thus, if insertion, deletion or genome re-arrangement, modifying or creating a Sma I or Cla I restriction site, 
does not occur, a distinct hybridisation band will correspond to one IS256 copy.

The discrimination of BEC isolates could be increased when the IS256 probe was hybridised with SmaIdigested genomic DNA (Table 1). Analysis of the SmaI/IS256 polymorphisms with the criterion of one band difference, gave 15 different patterns (I-XV, Fig 2) for the BEC isolates. These criteria allowed the differentiation of the PFGE subtype $A_{1}$ into nine patterns (I-IX, Fig. 2). The combination of PFGE and SmaI/IS256 techniques had a specificity of c. $85 \%$, when SmaI/IS256 polymorphism was compared with the association of PFGE with mecA, Tn554 and IS257 probe fingerprinting.

The frequency with which these IS256 patterns occurred among the $57 \mathrm{~A}_{1}$ PFGE isolates is given in Table 2. The association of IS256 polymorphism with the other techniques tested did not further improve the subtyping of the $23 \mathrm{~A}_{1}: \mathrm{I}$ isolates, even when ClaI/ IS256 polymorphism was used. Although 24 different ClaI/IS256 patterns were obtained for the 78 BEC isolates (Table 1), the methodology was not stable after in-vitro or in-vivo passages. Variations in the hybridisation patterns up to three band differences were verified for a unique isolate with this technique, as shown below.

\section{Stability of IS256 after in-vivo or in-vitro passages}

Because IS elements inherently have the potential to cause genetic re-arrangements, the stability of the methodologies was tested with IS256 [38]. For this purpose, the reproducibility was evaluated using six pairs of strains obtained before and after in-vivo or invitro passages. The study verified that the PFGE pattern (Fig. 3a) and SmaI/IS256 polymorphism (Fig. $3 b)$ did not show any alteration after these passages. As well as the stability of these techniques, slight changes in the Cla I/IS256 polymorphisms were verified for three pairs that were submitted to in-vitro passages (BVTP1/AVTP1 and BVTP2/AVTP2) or in-vivo passages (BVVP2/AVVP2). However, these changes never involved more than three bands and they were probably due to one or two genetic events after the in-vitro (about 2000 generations) or in-vivo passages (Fig. 3c).

\section{Discussion}

DNA technology has been intensively applied to the study of the molecular epidemiology of outbreaks. Various methods has been suggested for the characterisation of many different pathogenic bacteria [45-47]. Chromosomal DNA fingerprinting is a technique of

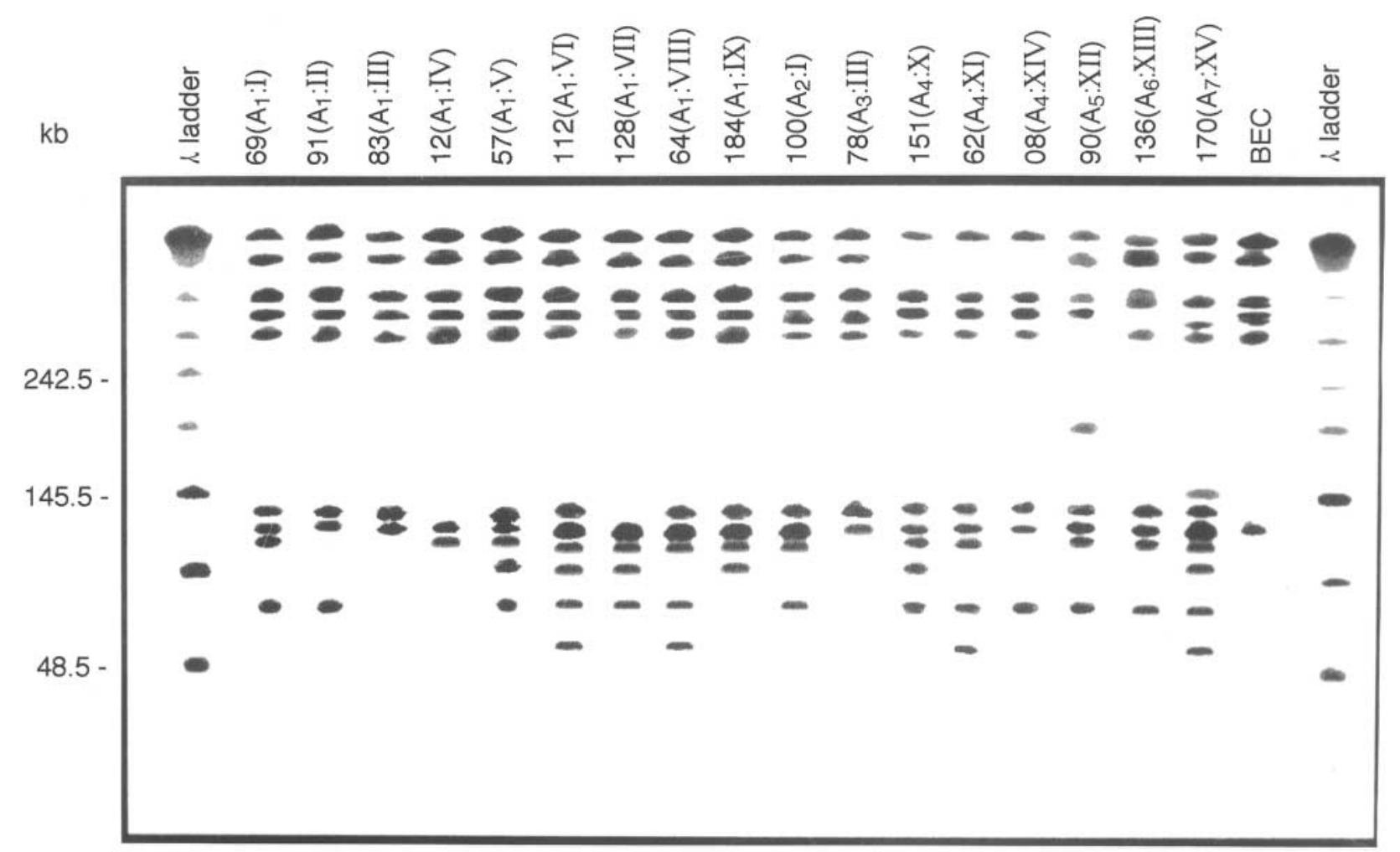

Fig. 2. Different SmaI/IS256 polymorphisms obtained for BEC strains. Lanes 1 and 19, $\lambda$ ladder; 2-10, patterns I-IX identified among the strains displaying PFGE pattern $A_{1} ; \mathbf{1 1 - 1 8}$, patterns I, III and $\mathbf{X}-\mathbf{X V}$ displayed by isolates with PFGE patterns $\mathrm{A}_{2}-\mathrm{A}_{7}$, respectively. 
increasing interest to epidemiologists evaluating and controlling nosocomial and community infections. This strategy is highly sensitive to minor genomic differences. Although various molecular techniques have been used to type MRSA strains, PFGE is considered discriminatory, reproducible and applicable to epidemiological studies involving MRSA [13, 22, 23, $32,34]$. Currently, there is a consensus among molecular epidemiologists that PFGE is the method of choice for genotyping bacteria associated with community- or hospital-associated outbreaks [32, 47, 48]. In the present study, the great majority of MRSA isolates obtained from the period 1996-1998 from Teresina city, Pi, displayed identical or very similar PFGE patterns, limiting the use of this technique as a powerful tool for bacterial genotyping.

Clonal spread of MRSA and the epidemic behaviour of some specific MRSA clones have been documented in several countries [9-24,30]. The BEC is an MRSA clone well adapted not only to cause hospitalassociated diseases in many countries, but also to support acquisition of new genetic traits without affecting its virulence or extraordinary ability to spread $[33,49,50]$. The wide spread of BEC isolates in the hospitals studied and in many other hospitals in Brazil, as well as in other countries, prompted an investigation of the value of different typing methods in detecting minor genomic variations among BEC isolates, in order to establish a methodology that would help in the studies of molecular epidemiology of outbreaks involving $\mathrm{BEC}$ isolates.

Other useful typing approaches, apart from PFGE, are chromosomal probe-fingerprinting techniques. In these methodologies the fragmented genomic DNA is transferred by blotting on to nylon or nitrocellulose membranes and the location of a subset of fragments containing a particular nucleotide sequence can be identified by hybridisation with the specific labelled DNA or RNA probe [45-47].

$m e c A$ or Tn554 probes, in combination with PFGE, have been used extensively for characterisation of MRSA [9-19, 32, 41]. The present study verified that the association of $C l a \mathrm{I} / m e c A$ and ClaI/Tn554 polymorphism generated only three types among the isolates displaying PFGE pattern $\mathrm{A}_{1}$ studied: patterns $\mathrm{A}_{1}: \mathrm{III}_{1}:: \mathrm{B}_{1}, \mathrm{~A}_{1}: \mathrm{III}:: \mathrm{B}_{1}$ and $\mathrm{A}_{1}: \mathrm{III}_{1}:: \mathrm{B}$. Furthermore, 47 of 57 BEC strains displaying PFGE $A_{1}$ pattern were typed as $\mathrm{A}_{1}: \mathrm{III}_{1}:: \mathrm{B}_{1}$. Moreover, a unique physical location (band $\mathrm{G}$ of $115 \mathrm{~kb}$ ) was observed when the mecA probe was hybridised with Sma I-digested genomic DNA for the great majority of the isolates studied. The lower discriminatory power of these methodologies showed that the degree of variability in the genome regions flanking these target sequences is very low among BEC isolates. Thus, the genomic diversity detected by these probes was very limited for genotyping these strains. Similar results were obtained by Tenover et al. when testing different epidemic MRSA clones [32].

The combination of IS257 or IS256 probe-fingerprinting with PFGE and conventional gel electrophoresis (CE) was also used to further discriminate BEC isolates. The IS257 probe-fingerprinting techniques did not discriminate BEC isolates when Cla I-digested DNA was used. All isolates displayed equal patterns (polymorphism $\alpha$ ). Similarly, when Sma I-cut DNA was tested, only three profiles $\left(a_{1}, a_{2}\right.$ and $\left.a_{3}\right)$ were obtained. In contrast, Yoshida et al. distinguished MRSA isolates sharing an identical PFGE type into eight distinct genotypes by IS257 typing [34]. This lack of agreement is probably due to the fact that all BEC isolates so far analysed in this laboratory from 1992 to the present displayed a small and constant number of IS257 copies inserted in the genome of BEC strains (two copies). In contrast, the strains analysed by Yoshida and co-workers, isolated from Malaya University Hospital, Japan, in the period 1987-1989, had a variable number of IS257 copies (two-to-five copies).

Some researchers have proposed the use of IS256 for genotyping MRSA strains [23,35-37]. Morvan et al., in 1997, verified that SmaI/IS256 polymorphism improved RFLP analysis by PFGE for discriminating between the intra-hospital, outbreak-related, phage type 77 MRSA strains and endemic strains disseminated in various cities and countries [23]. Similarly, in the present study, the $78 \mathrm{MRSA}$ isolates belonging to BEC clone type were discriminated into 15 different SmaI/ IS256 patterns. Among them, the 57 PFGE $\mathrm{A}_{1}$ isolates gave nine distinct SmaI/IS256 polymorphisms.

The discrimination of BEC isolates could not be improved when the IS256 probe was hybridised with Cla I-digested DNA, separated by conventional DNA gel electrophoresis. Although this typing method differentiated BEC strains into 24 different patterns, it was not sufficiently stable for the analysis of BEC strains involved in hospital outbreaks. The method showed poor reproducibility after in-vivo or in-vitro passages of these MRSA isolates. The fact that Cla I restriction endonuclease cuts the genomic DNA into numerous fragments, associated with the high number of IS256 copies verified in the genome of BEC isolates (9-15 copies), could explain the poor reproducibility of this method. Moreover, IS256 can mediate genomic re-arrangements and these changes can be detected after in-vitro manipulation when enzymes that cut DNA frequently are used $[30,36]$.

In conclusion, Cla I/mecA，Cla I/Tn554，ClaI/IS257, SmaI/mecA and SmaI/IS257 polymorphisms do not efficiently discriminate BEC isolates; therefore, the use of these techniques as molecular strategies is not recommended for genotyping these strains.

It is of concern that when infections caused by the 
a
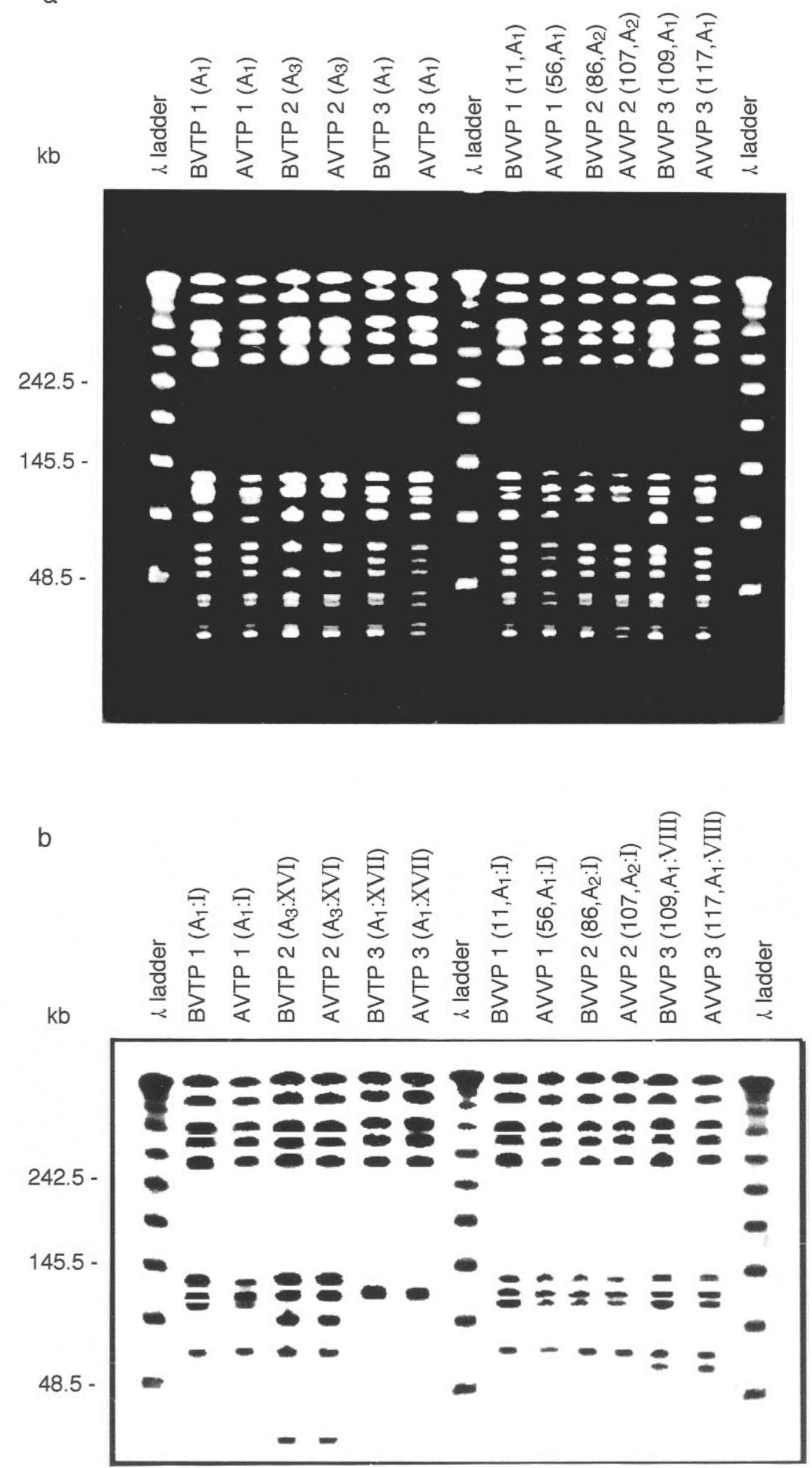


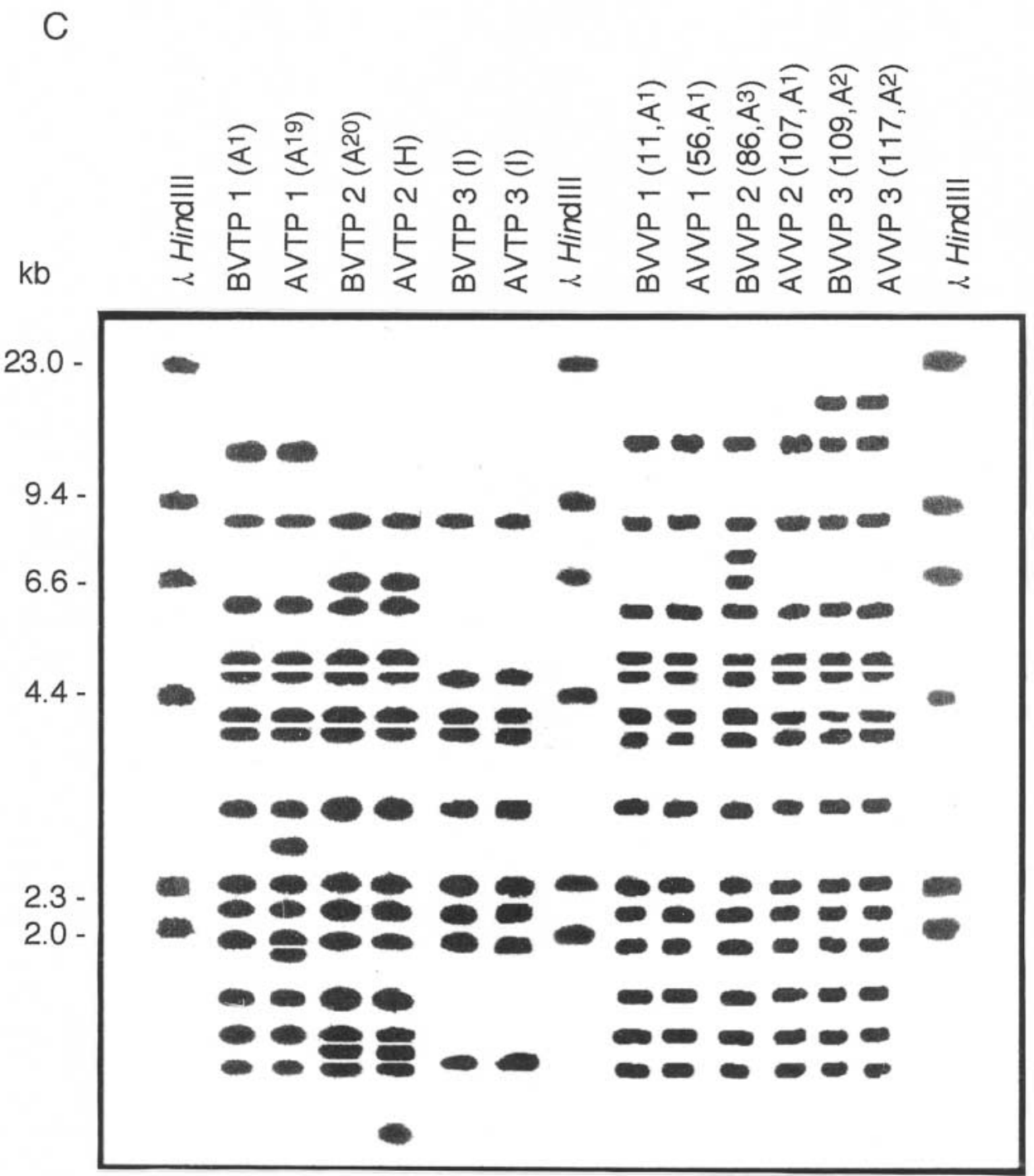

Fig. 3. (a) PFGE patterns obtained for the strains belonging to BEC clone type before or after in-vitro or in-vivo passages. Lanes 1, 8 and 15, $\lambda$ ladder; 2-7, pairs 1,2 and 3 before and after in-vitro passages (BVTP and AVTP, respectively); 8-14, pairs 11/56, 86/107 and 109/117 collected from three different patients before (BVVP) and after (AVVP) periods of 1 week to 2 months. (b) SmaI/IS256 polymorphisms displayed by pairs of strains obtained before or after passages. Lanes $\mathbf{1}, \mathbf{8}$ and 15, $\lambda$ ladder; $\mathbf{2}-\mathbf{7}$, patterns displayed by pairs of strains $(1,2$ and 3$)$ before or after invitro passages (BVTP, AVTP, respectively); 8-14, patterns displayed by pairs of strains $(11 / 56,86 / 107$ and 109/117) collected from three different patients before (BVVP) or after (AVVP) periods of 1 week to 2 months. (c) Cla I/IS256 polymorphisms presented by pairs of strains obtained before or after passages. Lanes 1, 8 and 15, $\lambda$ HindIII; 2-7, patterns displayed by pairs of strains $(1,2$ and 3$)$ before or after in-vitro passages (BVTP, AVTP, respectively); 8-14, patterns displayed by pairs of strains $(11 / 56,86 / 107$ and 109/117) obtained from three different patients before (BVVP) or after (AVVP) periods of 1 week to 2 months.

same bacterial species affect different patients in a unit, infection control measures could be improved by making use of the molecular epidemiological analysis of the strains involved [47]. On the basis of the results of the present study, it is concluded that the inclusion of SmaI/IS256 probe-fingerprinting as an approach to detect variants of $\mathrm{BEC}$ displaying $\mathrm{PFGE} \mathrm{A}_{1}$ pattern enhances the ability to distinguish BEC strains associated with intra-hospital infections. Thus, the use of this probe fingerprinting in epidemiological studies involving strains from BEC clone type may be recommended. Also, it would appear that the use of IS probes in combination with PFGE could be a useful strategy to further characterise other clusters of MRSA isolates.

This work was supported by grants from Conselho Nacional de Desenvolvimento Cientifico e Tecnológico (CNPq) to A.M.S.F. and L.A.T., Financiadora de Estudos e Projetos (FINE/PRONEX) to A.M.S.F. and Fundação de Amparo à Pesquisa do Estado do Rio de Janeiro (FAPERJ) to A.M.S.F., B.T.F.C. and L.A.T.

\section{References}

1. Archer GL. Staphylococcus aureus: a well-armed pathogen. Clin Infect Dis 1998; 26: 1179-1181.

2. Voss A, Milatovic D, Wallrauch-Schwarz C, Rosdahl VT, 
Braveny I. Methicillin-resistant Staphylococcus aureus in Europe. Eur J Clin Microbiol Infect Dis 1994; 13: 50-55.

3. Lyon BR, Skurray R. Antimicrobial resistance of Staphylococcus aureus: genetic basis. Microbiol Rev 1987; 51: 88-134.

4. Jevons MP. "Celbenin"-resistant staphylococci. BMJ 1961; 1: $124-125$.

5. Pavillard R, Harvey K, Douglas D et al. Epidemic of hospitalacquired infection due to methicillin-resistant Staphylococcus aureus in major Victorian hospitals. Med J Aust 1982; 1: $451-454$.

6. Cookson BD, Phillips I. Epidemic methicillin-resistant Staphylococcus aureus. J Antimicrob Chemother 1988; 24 Suppl C: $57-65$.

7. Kerr S, Kerr GE, Mackintosh CA, Marples RR. A survey of methicillin-resistant Staphylococcus aureus affecting patients in England and Wales. J Hosp Infect 1990; 16: 35-48.

8. Marples RR, Cooke EM. Current problems with methicillinresistant Staphylococcus aureus. J Hosp Infect 1988; 11: $381-392$.

9. Dominguez MA, de Lencastre H, Linares J, Tomasz, A. Spread and maintenance of a dominant methicillin-resistant Staphylococcus aureus (MRSA) clone during an outbreak of MRSA disease in a Spanish hospital. J Clin Microbiol 1994; 32: 2081-2087.

10. Teixeira LA, Resende CA, Ormonde LR et al. Geographic spread of epidemic multiresistant Staphylococcus aureus clone in Brazil. J Clin Microbiol 1995; 33: 2400-2404.

11. Santos Sanches I, Ramirez M, Troni H et al. Evidence for the geographic spread of a methicillin-resistant Staphylococcus aureus clone between Portugal and Spain. J Clin Microbiol 1995; 33: $1243-1246$.

12. Santos Sanches I, Aires de Sousa M, Cleto L, Campos MB, de Lencastre H. Tracing the origin of an outbreak of methicillinresistant Staphylococcus aureus infections in a Portuguese hospital by molecular fingerprinting methods. Microb Drug Resist 1996; 2: 319-329.

13. Aires de Sousa M, Santos Sanches I, van Belkum A, van Leeuwen W, Verbrugh H, de Lencastre H. Characterization of methicillin-resistant Staphylococcus aureus isolates from Portuguese hospitals by multiple genotyping methods. Microb Drug Resist 1996; 2: 331-341.

14. Corso A, Santos Sanches I, Aires de Sousa M, Rossi A, de Lencastre H. Spread of a methicillin-resistant and multiresistant epidemic clone of Staphylococcus aureus in Argentina. Microb Drug Resist 1998; 4: 277-288.

15. Aires de Sousa M, Santos Sanches I, Ferro ML et al. Intercontinental spread of a multidrug-resistant methicillinresistant Staphylococcus aureus clone. J Clin Microbiol 1998; 36: 2590-2596.

16. Mato R, Santos Sanches I, Venditti M et al. Spread of the multiresistant Iberian clone of methicillin-resistant Staphylococcus aureus (MRSA) to Italy and Scotland. Microb Drug Resist 1998; 4: 107-112.

17. Roberts RB, Tennenberg AM, Eisner W et al. Outbreak in a New York city teaching hospital burn center caused by the Iberian epidemic clone of MRSA. Microb Drug Resist 1998; 4: $175-183$.

18. Sá-Leão R, Santos Sanches I, Dias D, Peres I, Barros RM, de Lencastre H. Detection of an archaic clone of Staphylococcus aureus with low-level resistance to methicillin in a pediatric hospital in Portugal and in international samples: relics of a formerly widely disseminated strain? J Clin Microbiol 1999; 37: $1913-1920$.

19. Melter O, Santos Sanches I, Schindler J et al. Methicillinresistant Staphylococcus aureus clonal types in the Czech Republic. J Clin Microbiol 1999; 37: 2798-2803.

20. Da Silva Coimbra MV, Teixeira LA, Ramos RLB et al. Spread of the Brazilian epidemic clone of a multiresistant MRSA in two cities in Argentina. J Med Microbiol 2000; 49: 187-192.

21. Da Silva Coimbra MV, Hall G, Tallent S et al. Clonal spread of methicillin-resistant Staphylococcus aureus in a large geographic area of the United States. In: Program and Abstracts of the 39th ICAAC, 1999, San Francisco, CA. American Society for Microbiology; 1999: 162.

22. van Belkum A, van Leeuwen W, Verkooyen R, Saçilik SC, Cokmus C, Verbrugh H. Dissemination of a single clone of methicillin-resistant Staphylococcus aureus among Turkish hospitals. J Clin Microbiol 1997; 35: 978-981.

23. Morvan A, Aubert S, Godard C, El Sohl N. Contribution of a typing method based on IS256 probing of SmaI-digested cellular DNA to discrimination of European phage type 77 methicillin-resistant Staphylococcus aureus strains. J Clin Microbiol 1997; 35: 1415-1423.

24. Tanaka T, Okuzumi K, Iwamoto A, Hiramatsu K. A retrospective study of methicillin-resistant Staphylococcus aureus clinical strains in Tokyo University hospital. J Infect Chemother 1995; 1: 40-49.

25. Sader HS, Pignatari AC, Hollis RJ, Jones RN. Evaluation of interhospital spread of methicillin-resistant Staphylococcus aureus in São Paulo, Brazil, using pulsed-field gel electrophoresis of chromosomal DNA. Infect Control Hosp Epidemiol 1994; 15: 320-323

26. Santos Filho L, Sader HS, Bortolotto VI, Gontijo Filho PP, Pignatari AC. Analysis of the clonal diversity of Staphylococcus aureus methicillin-resistant strains isolated at João Pessoa, State of Paraíba, Brazil. Mem Inst Oswaldo Cruz 1996; 91: 101-105.

27. Santos KRN, Teixeira LM, Leal GS, Fonseca LS, Gontijo Filho PP. DNA typing of methicillin-resistant Staphylococcus aureus: isolates and factors associated with nosocomial acquisition in two Brazilian university hospitals. J Med Microbiol 1999; 48: 17-23.

28. Soares MJS, Araújo GL, Silva PV, Silva-Carvalho MC, Teixeira LA, Figueiredo AMS. Molecular characterization of methicillin-resistant Staphylococcus aureus belonging to the Brasilian Epidemic Clone isolated in Montreal (Quebec) in the early 1990s. In: 40th Interscience Conference on Antimicrobial Agents and Chemotherapy. Toronto, Ontário, Canada, September 17-20/2000a. Poster Session, Presentation no. 158

29. Carles-Nurit MJ, Christophle B, Broche S, Gouby A, Bouziges $\mathrm{N}$, Ramuz M. DNA polymorphisms in methicillin-susceptible and methicillin-resistant strains of Staphylococcus aureus. J Clin Microbiol 1992; 30: 2092-2096.

30. Kreiswirth B, Kornblum J, Arbeit RD et al. Evidence for a clonal origin of methicillin resistance in Staphylococcus aureus. Science 1993; 259: 227-230.

31. Dyke KGH, Aubert S, El Solh N. Multiple copies of IS256 in staphylococci. Plasmid 1992; 28: 235-246.

32. Tenover FC, Arbeit R, Archer G et al. Comparison of traditional and molecular methods of typing isolates of Staphylococcus aureus. J Clin Microbiol 1994; 32: 407-415.

33. dos Santos Soares MJ da Silva-Carvalho MC, FerreiraCarvalho BT, Figueiredo AMS. Spread of methicillin-resistant Staphylococcus aureus belonging to the Brazilian epidemic clone in a general hospital and emergence of heterogenous resistance to glycopeptide antibiotics among these isolates. $J$ Hosp Infect 2000; 44: 301-308.

34. Yoshida T, Kondo N, Hanifah YA, Hiramatsu K. Combined use of ribotyping, PFGE typing and IS431 typing in the discrimination of nosocomial strains of methicillin-resistant Staphylococcus aureus. Microbiol Immunol 1997; 41: 687-695.

35. Monzon-Moreno C, Aubert S, Morvan A, El Solh N. Usefulness of three probes in typing isolates of methicillinresistant Staphylococcus aureus (MRSA). J Med Microbiol 1991; 35: 80-88

36. Wei M-Q, Udo EE, Grubb WB. Typing of methicillin-resistant Staphylococcus aureus with IS256. FEMS Microbiol Lett 1992; 99: $175-180$.

37. Arpin C, Lagrange I, Gachie JP, Bebear C, Quentin C. Epidemiological study of an outbreak of infection with Staphylococcus aureus resistant to lincosamides and streptogramin A in a French hospital. J Med Microbiol 1996; 44: 303-310.

38. Galas DJ, Chandler M. Bacterial insertion sequences. In: Berg DE, Howe MM (eds) Mobile DNA. Washington, DC American Society for Microbiology. 1989: 109-162.

39. Lyon BR, Gillespie MT, Skurray RA. Detection and characterization of IS256, an insertion sequence in Staphylococcus aureus. J Gen Microbiol 1987; 133: 3031- 3038.

40. Barberis-Maino L, Berger-Bächi B, Weber H, Beck WD, Kayser FH. IS431, a staphylococcal insertion sequence-like element related to IS26 from Proteus vulgaris. Gene 1987; 59: 107-113.

41. de Lencastre H, Couto I, Santos I, Melo-Cristino J, TorresPereira A, Tomasz A. Methicillin-resistant Staphylococcus aureus disease in a Portuguese hospital: characterization of clonal types by a combination of DNA typing methods. Eur $J$ Clin Microbiol Infect Dis 1994; 13: 64-73.

42. Matthews P, Tomasz A. Insertional inactivation of the mec gene in a transposon mutant of a methicillin-resistant clinical 
isolate of Staphylococcus aureus. Antimicrob Agents Chemother 1990; 34: 1777-1779.

43. Needham C, Rahman M, Dyke KGH, Noble WC. An investigation of plasmids from Staphylococcus aureus that mediate resistance to mupirocin and tetracycline. Microbiology 1994; 140: 2577-2583

44. Byrne ME, Rouch DA, Skurray RA. Nucleotide sequence analysis of IS256 from the Staphylococcus aureus gentamicintobramycin-kanamycin-resistance transposon Tn4001. Gene 1989; 81: 361-367.

45. Maslow JN, Mulligan ME, Arbeit RD. Molecular epidemiology: application of contemporary techniques to the typing of microorganisms. Clin Infect Dis 1993; 17: 153-164.

46. Tenover FC, Arbeit RD, Goering RV, the Molecular Typing Working Group of the Society for Healthcare Epidemiology of America. How to select and interpret molecular strain typing methods for epidemiological studies of bacterial infectious: a review for healthcare epidemiologists. Infect Control Hosp Epidemiol 1997; 18: 426-439.
47. Goering RV. The molecular epidemiology of nosocomial infection: an overview of principles, application, and interpretation. In: Specter S, Mauro B, Herman F (eds) Rapid detection of infectious agents. New York, Plenum Press. 1998: $131-157$.

48. Struelens MJ, Deplano A, Godard C, Maes N, Serruys E. Epidemiologic typing and delineation of genetic relatedness of methicillin-resistant Staphylococcus aureus by macrorestriction analysis of genomic DNA by using Pulsed-Field Gel Electrophoresis. J Clin Microbiol 1992; 30: 2599-2605.

49. Ramos RLB, Teixeira LA, Ormonde LR et al. Emergence of mupirocin resistance in multiresistant Staphylococcus aureus clinical isolates belonging to Brazilian epidemic clone III::B:A. J Med Microbiol 1999; 48: 303-307.

50. Soares MJS, Tokumaru-Miyazaki NH, Noleto ALS, Figueiredo AMS. Enterotoxin production by Staphylococcus aureus clones and detection of Brazilian epidemic MRSA clone (III::B:A) among isolates from food handlers. J Med Microbiol 1997; 46: 214-221. 